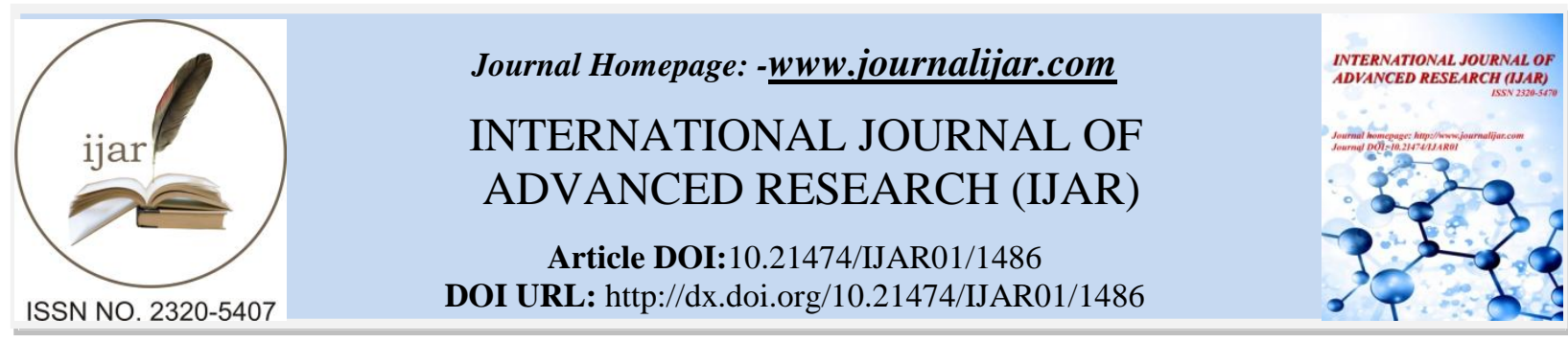

RESEARCH ARTICLE

\title{
VISION OF IMPACT OF HYPERTENSION IN THE SOCIETY LOOKING FOR TO REDUCE COMPLICATION AND IMPROVE OUTCOME.
}

\author{
*Dr Ashgar Eman Manaji ${ }^{1}$, Alhassan, Ahmed Hassan A ${ }^{2}$, Salah Same, Mohammed $\mathbf{R}^{3}$, Salah Rozan, \\ Mohammed $\mathbf{R}^{3}$, Magharbel Rehamshakir $\mathbf{B}^{4}$,Altwairqi Elaf Sulaiman $\mathbf{M}^{4}$, AlrahmaniDana Ayed \\ $\mathbf{M}^{4}$,Namnqani Raghad Mohammed I ${ }^{5}$, Patel Asma Imtiaz I ${ }^{6}$, Wejdan Abdullah Alqarni ${ }^{6}$, Ali Reem Abdulaziz \\ $A^{6}$, Sanyour Ghazal Omar ${ }^{6}$, Mohammed Talal Al-Nazzawi ${ }^{6}$, Alhazmi Samar Saeed Saleem . \\ 1. Consultant Cardiology, King Fahad General Hospital Jeddah. \\ 2. College Of Medicine University Of Jeddah, Jeddah Ksa. \\ 3. College Of Medicine, University Of Szeged, Hungary. \\ 4. College Of Medicine, King Abdulaziz University, Jeddah Ksa. \\ 5. College Of Medicine, Ibn Sina National College, Jeddah Ksa. \\ 6. College Of Medicine, Batterjjee Medical College, Jeddah Ksa. \\ 7. Saint Mary's University, Halifax, Canada.
}

\section{Manuscript Info}

\section{Manuscript History}

Received: 12 July 2016

Final Accepted: 19 August 2016

Published: September 2016

\section{Abstract}

Objectives:- There are three objectives for this study. Firstly, is to determine the prevalence of moderate risk factors of hypertension. Secondly, is to avoid and delay the development of complications within the next five to ten years. Thirdly, is to educate people at risk and modify their life style to live a better and a healthier life.

Study design:- A Randomised (Cross-sectional) study.

Settings:The study was conducted in KSA, in the city of Jeddah, at Al-Balad- Historic Jeddah festival during the month of Ramadan.

Subjects:- A total of 3231 people (2200 were interviewed and the other 1031 only filled the questionnaire) were investigated. Females were more than males investigated in the study with a percentage of $54.5 \%$ for females and $45.5 \%$ for males. Saudis were $83 \%$ whereas $16.7 \%$ were non-Saudis. A (12\%) of total respondents had diagnosed with hypertension, in which $(85.1 \%)$ were Saudis (14.9\%), females were $(50.4 \%)$ and $(30.8 \%)$ were male with hypertension.

Results:- A (12\%) of total respondents had diagnosed with hypertension, in which $(85.1 \%)$ were Saudis $(14.9 \%)$, females were $(50.4 \%)$ and $(30.8 \%)$ were male with hypertension. Of the 3231 participants, there were $(30.9 \%)$ overweight, $(21.0 .9 \%)$ were obese and $(4.9 \%)$ were morbidly obese. Regarding the family history of hypertension $(20.9 \%)$ had no family history and only (31.9\%) with a positive family history. Smoking habits were $(68.1 \%)$ and nonsmokers $(52.2 \%)$. On the other hand, people who practiced exercise were $(47.8 \%)$ and not exercising were only $(17.2 \%)$. (10\%) of the participants were diagnosed with diabetes mallets, in which (29.3\%) of them were overweight, (20\%) were obese and (4.7\%) morbidly obese.

Corresponding Author:- Ashgar Eman Manaji.

Address:- Consultant cardiology, King Fahad General Hospital Jeddah. 
Conclusion:- smokers were more likely to diagnosed with hypertension. $(\mathrm{OR}=1.41,95 \% \mathrm{CI}=1.12-1.77 ; \mathrm{P}=.003)$. higher chance to diagnose with hypertension if there was positive family history $(\mathrm{OR}=1.69,95 \% \mathrm{CI}=1.30-2.19 ; \mathrm{P}=.000)$. Who don't drink energy drinks had higher risk $(\mathrm{OR}=1.04,95 \% \mathrm{CI}=1.02-1.07 ; \quad \mathrm{P}=.003)$. Diagnosis with hypertension highly correlated with the increment of BMI $(\mathrm{P}=.000)$, and also with older population $(\mathrm{p}=.00)$. no correlation between exercise frequency and diagnosis of hypertension $(\mathrm{p}=.085)$. It was found that there was no significant difference between female and male who were diagnosed with hypertension. The interesting significance we found in this study, many of our participant with hypertension had no positive family history but they were either smokers or morbidly obese or even both risk factors. We must emphasize that management of the modifiable risk factors of hypertension reduces the risk of cardiovascular insult, renal damage, stroke and ischemic heart disease.

Copy Right, IJAR, 2016,. All rights reserved.

\section{Introduction:-}

Hypertension is defined as persistent elevation of SBP $\geq 140 \mathrm{~mm} \mathrm{Hg}$ and/or DBP $\geq 90 \mathrm{~mm} \mathrm{Hg}$ in adults not on antihypertensive medications ${ }^{(1)}$. Blood pressure can be raised normally when the person is under certain conditions for instance after exercise or under stress. Hypertension is a silent disease, elevated blood pressure for a short duration is normal but when it is elevated for a long term it can cause a serious health problem. Hypertension can be primary which is caused by environmental or genetic factors and accounts for $90-95 \%$ of the cases. Secondary hypertension is due to renal, vascular and endocrine causes and accounts for $2-10 \%$ of the cases ${ }^{(2)}$. Serious illnesses which can be caused by prolonged term of uncontrollable blood pressure include coronary artery disease, heart failure, peripheral vascular disease, retinopathy, stroke, eclampsia and chronic kidney disease ${ }^{(2,3)}$. There is no definite signs and symptoms by which hypertension can be diagnosed, few hypertensive patients may experience headache, shortness of breath and nose bleeding which are nonspecific symptoms ${ }^{(1)}$.Mainly hypertension is diagnosed accidentally while a routine checks up where the blood pressure is higher than $120 / 80 \mathrm{mmHg}$ but one reading is not efficient so it should be monitored for several times and documented, or it can be diagnosed accidentally after having emergency caused by an organ damage. Measuring for blood pressure is simple, cost effective and can be done by mercury sphygmomanometer, auscultatory, oscillometricsemiautomated or fully automated devices. According to severity and degrees of hypertension management plan is made and antihypertensive medication is prescribed ${ }^{(2,3,4)}$. Those patients need to be seen on a monthly interval to monitor their blood pressure and risk factors as well as the effectiveness of the treatment, the scheduling of the visit can be made in every three to six months once the goal blood pressure is established.

Ramadan is a holy month in which every Muslim fast and changes his/her life style during this month, according to many studies done in the past, fasting shows a beneficial effect on blood pressure. The hypothesis behind it is due to inhibition of the basic metabolism and decrease the effect of the sympathetic on the heart muscles known as myocardium and smooth muscles of the vessels. ${ }^{(1)}$

Depending on the recent study done in Saudi Arabia, blood pressure levels are classified into the following:

\begin{tabular}{|l|l|l|}
\hline Category & SBP $(\mathbf{m m H g})^{*}$ & DBP $(\mathbf{m m H g})^{*}$ \\
\hline Normal & $<120$ & $<80$ \\
\hline Pre-HTN & $120-139$ & $80-89$ \\
\hline HTN: grade I & $140-159$ & $90-99$ \\
\hline HTN: grade II & $160-179$ & $100-109$ \\
\hline HTN: grade III & $>180$ & $>110$ \\
\hline
\end{tabular}

Table 1: classification of blood pressure in Adult. SPS: systolic blood pressure, DBP: diastolic blood pressure. ${ }^{(1)}$ 


\section{Justification:-}

Hypertension in kingdom of Saudi Arabia has become an increasingly important health problem affecting more than one fourth of the population. Uncontrolled hypertension considered as the main risk factor of cardiovascular disease, stroke, heart attack and other serious illness. An early detection and management of the risk factors limits the damage to the heart and arteries.

\section{Objectiveof the study:-}

- To determine the prevalence of moderate risk factors of hypertension.

- To avoid and delay the development of complications within the next 5-10 years.

- To educates those who are at risk and modify their life style to a better and health life.

\section{Material and methods:-}

Jeddah is one of the biggest city in the kingdom of Saudi Arabia with multi-cultural residents. Being such an important city, a commercial hub and dramatically growing in rate, we chose this beloved city to conduct our research specially in Al-balad during Ramadan where most of the people visits for the historic Jeddah festival.

\section{Study Area/Setting:-}

The study will be conducted at Al Balad - Historic Jeddah Festival

\section{Study Subjects:-}

Inclusion criteria:-

- Adults above 20 years old.

- Both Saudi and non-Saudi.

Exclusion criteria:-

- Ethnicity.

- Person diagnosed with Hypertension.

- Residents staying less than five years.

- Alcohol consumption.

\section{Study Design:-}

The type of research to be conducted is a randomized study.

\section{Data Collection Methods:-}

Data collection methods in this study include questionnaire, weighing scale, Stadiometer (Height scale), All measurements will be taken by trained medical interns and paramedics with reliable instruments.

Verbal consent will be taken after which the questionnaires will be filled using computer-based application. Then the person will be sent to obtain the remaining measurements which will be hand-filled on a prepared sheet and coordinated with the questionnaire information.

\section{The Result:-}

During this study period there were 3231 responses (2200 were interviewed and the other 1031 only filled the questionnaire). Most participants were female $(54.5 \%)$ and male were $(45.5 \%)$. Who had a level of educational in bachelor degree (63\%), higher education (7\%), high school (23.7\%), lesser extent elementary (1.8\%) and intermediate school (4.1\%). The majority of them are Saudi (83\%) and only (16.7\%) are non-Saudi. Regarding their marital status, a (48.9\%) were singles, $(48.2 \%)$ are married and $(2.3 \%)$ are divorced. As for the occupation the highest percentage were students (38\%), employed (37\%) and non-employed (24\%) in which (47\%) had a medical insurance. A (12\%) of total respondents had diagnosed with hypertension, in which (85.1\%) were Saudis (14.9\%), females were $(50.4 \%)$ and $(30.8 \%)$ were male with hypertension. Of the 3231 participants, there were $(30.9 \%)$ overweight, $(21.0 .9 \%)$ were obese and $(4.9 \%)$ were morbidly obese. Regarding the family history of hypertension (20.9\%) had no family history and only (31.9\%) with a positive family history. Smoking habits were $(68.1 \%)$ and non-smokers $(52.2 \%)$. On the other hand, people who practiced exercise were (47.8\%) and not exercising were only 
$(17.2 \%)$. (10\%) of the participants were diagnosed with diabetes mallets, in which $(29.3 \%)$ of them were overweight, $(20 \%)$ were obese and $(4.7 \%)$ morbidly obese.

Analyses demonstrate that smokers were more likely to diagnosed with hypertension $(\mathrm{OR}=1.41,95 \% \mathrm{CI}=1.12-1.77$; $\mathrm{P}=.003)$. higher chance to diagnose with hypertension if there was positive family history $(\mathrm{OR}=1.69,95 \% \mathrm{CI}=1.30$ $2.19 ; \mathrm{P}=.000)$. Who don't drink energy drinks had higher risk $(\mathrm{OR}=1.04,95 \% \mathrm{CI}=1.02-1.07 ; \mathrm{P}=.003)$. Diagnosis with hypertension highly correlated with the increment of BMI $(\mathrm{P}=.000)$, and also with older population ( $\mathrm{p}=.00)$. no correlation between exercise frequency and diagnosis of hypertension $(p=.085)$.

Data analysis on SPSS version 24

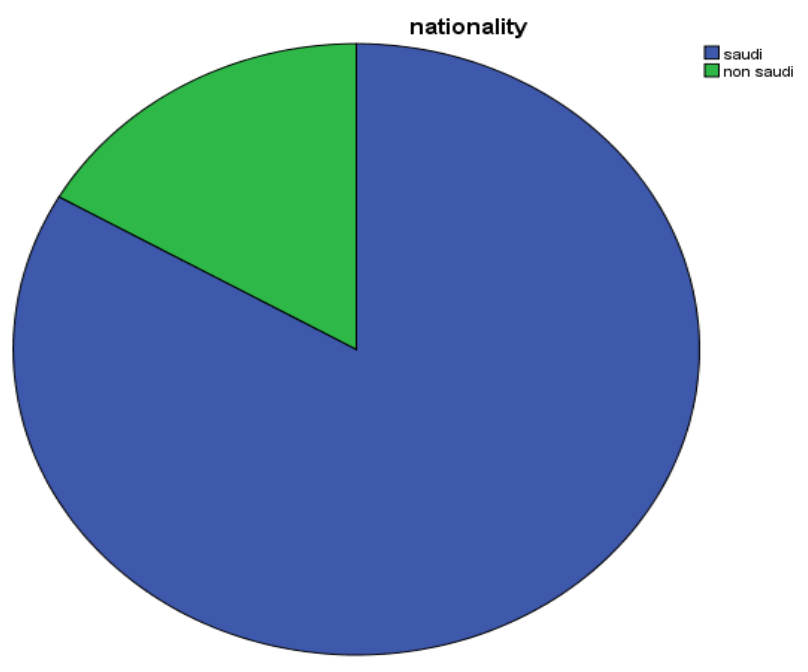

\begin{tabular}{|l|l|l|l|l|l|}
\hline \multicolumn{2}{|l|}{ education level } & Frequency & Percent & Valid Percent & Cumulative Percent \\
\hline \multirow{4}{*}{ Valid } & elementary school & 58 & 1.8 & 1.8 & 1.8 \\
\cline { 2 - 6 } & intermediate school & 132 & 4.1 & 4.1 & 5.9 \\
\cline { 2 - 6 } & high school & 766 & 23.7 & 23.7 & 29.6 \\
\cline { 2 - 6 } & bachelor degree & 2038 & 63.1 & 63.1 & 92.7 \\
\cline { 2 - 6 } & higher education & 236 & 7.3 & 7.3 & 100.0 \\
\cline { 2 - 6 } & Total & 3230 & 100.0 & 100.0 & \\
\hline
\end{tabular}

\begin{tabular}{|l|l|l|l|l|l|}
\hline \multicolumn{2}{|c|}{ nationality } & Frequency & Percent & Valid Percent & Cumulative Percent \\
\hline \multirow{3}{*}{ Valid } & Saudi & 2691 & 83.3 & 83.3 & 83.3 \\
\cline { 2 - 6 } & non Saudi & 539 & 16.7 & 16.7 & 100.0 \\
\cline { 2 - 6 } & Total & 3230 & 100.0 & 100.0 & \\
\hline
\end{tabular}




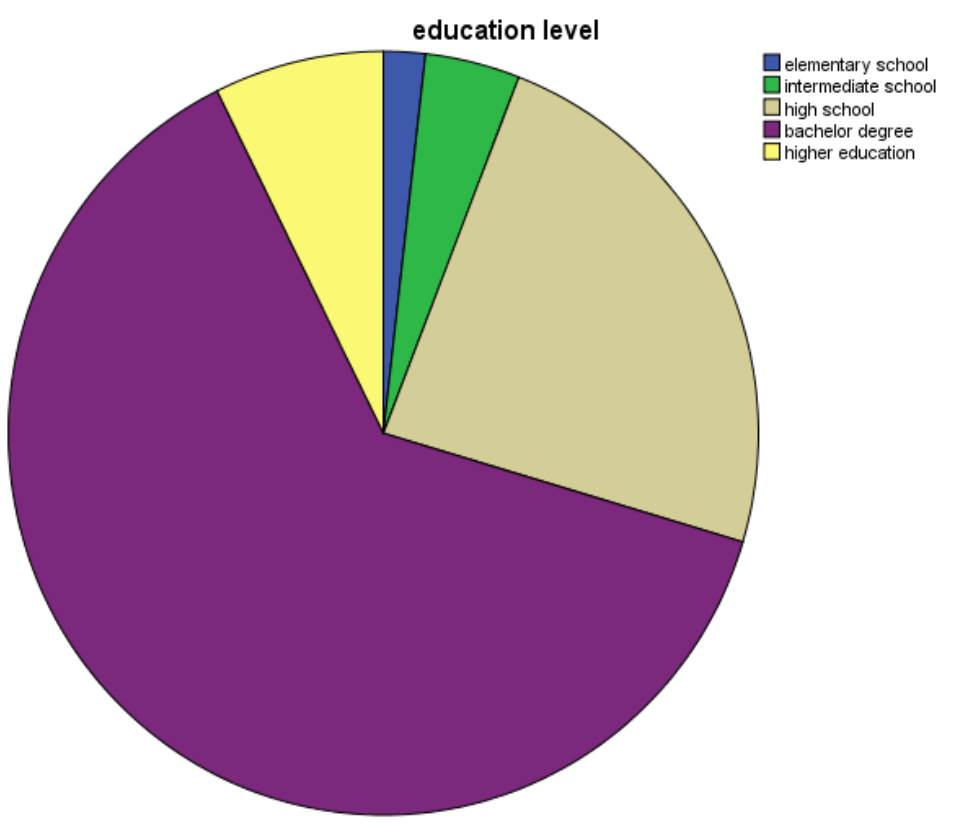

\begin{tabular}{|c|c|c|c|c|c|}
\hline \multicolumn{6}{|c|}{ medical insurance } \\
\hline & & Frequency & Percent & Valid Percent & Cumulative Percent \\
\hline \multirow[t]{3}{*}{ Valid } & yes & 1518 & 47.0 & 47.0 & 47.0 \\
\hline & no & 1712 & 53.0 & 53.0 & 100.0 \\
\hline & Total & 3230 & 100.0 & 100.0 & \\
\hline
\end{tabular}

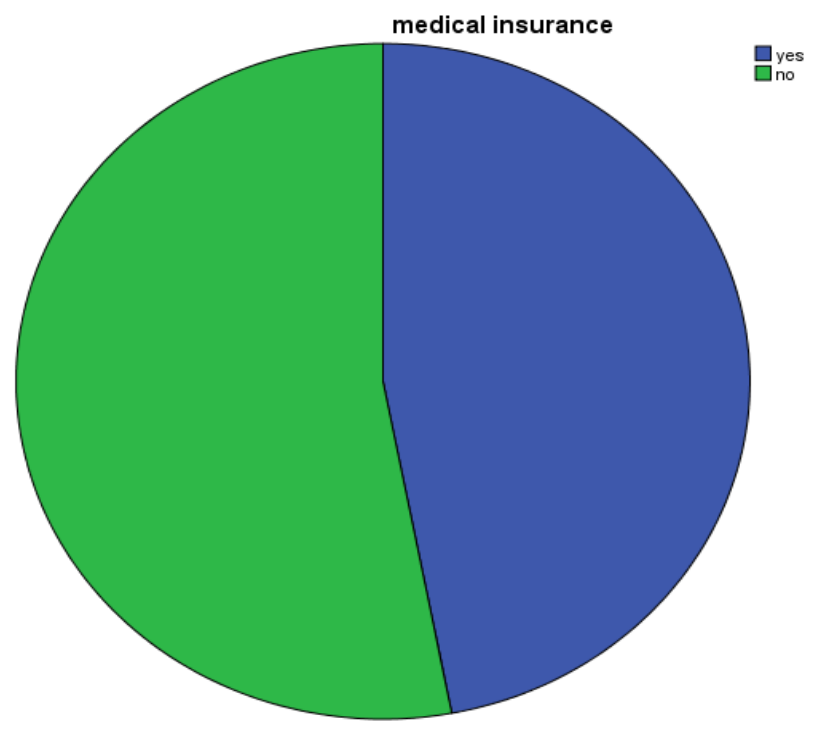

\begin{tabular}{|c|c|c|c|c|c|}
\hline \multicolumn{6}{|c|}{ do you exercise regularly? } \\
\hline & & Frequency & Percent & Valid Percent & Cumulative Percent \\
\hline \multirow[t]{3}{*}{ Valid } & yes & 1885 & 58.4 & 58.4 & 58.4 \\
\hline & no & 1345 & 41.6 & 41.6 & 100.0 \\
\hline & Tota & 3230 & 100.0 & 100.0 & \\
\hline
\end{tabular}




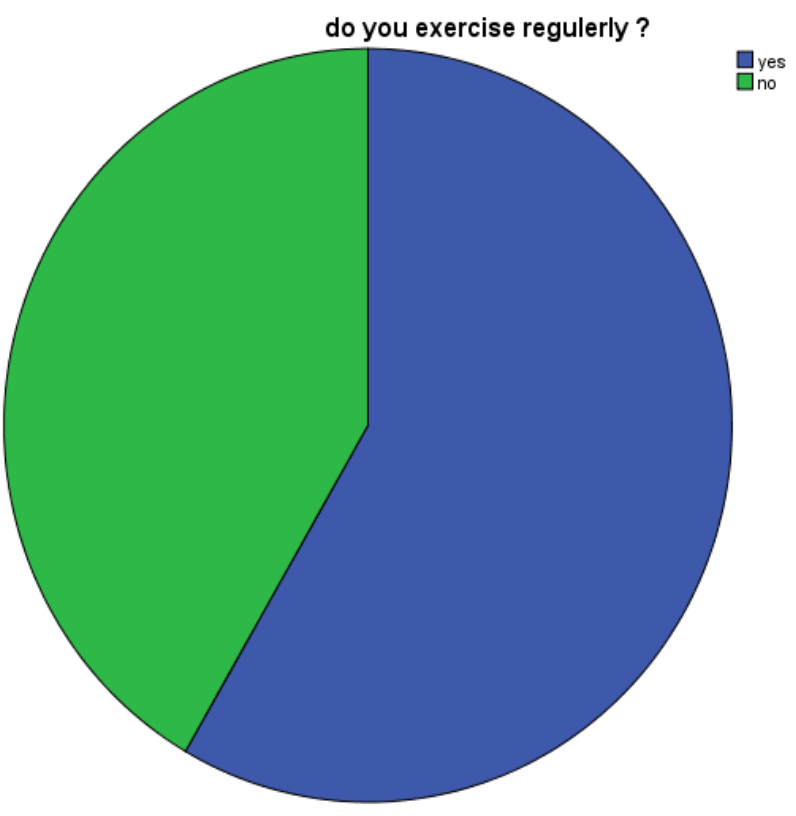

\begin{tabular}{|l|l|l|l|l|l|}
\hline \multicolumn{2}{|l|}{ how frequent do you exercise? } & Frequency & Percent & Valid Percent & $\begin{array}{l}\text { Cumulative } \\
\text { Percent }\end{array}$ \\
\hline \multirow{3}{*}{ Valid } & daily & 574 & 17.8 & 20.0 & 20.0 \\
\cline { 2 - 6 } & weekly & 853 & 26.4 & 29.8 & 49.8 \\
\cline { 2 - 6 } & monthly & 498 & 15.4 & 17.4 & 67.2 \\
\cline { 2 - 6 } & not exercising & 941 & 29.1 & 32.8 & 100.0 \\
\cline { 2 - 6 } & Total & 2866 & 88.7 & 100.0 & \\
\hline Missing & System & 364 & 11.3 & & \\
\hline Total & 3230 & 100.0 & & \\
\hline
\end{tabular}

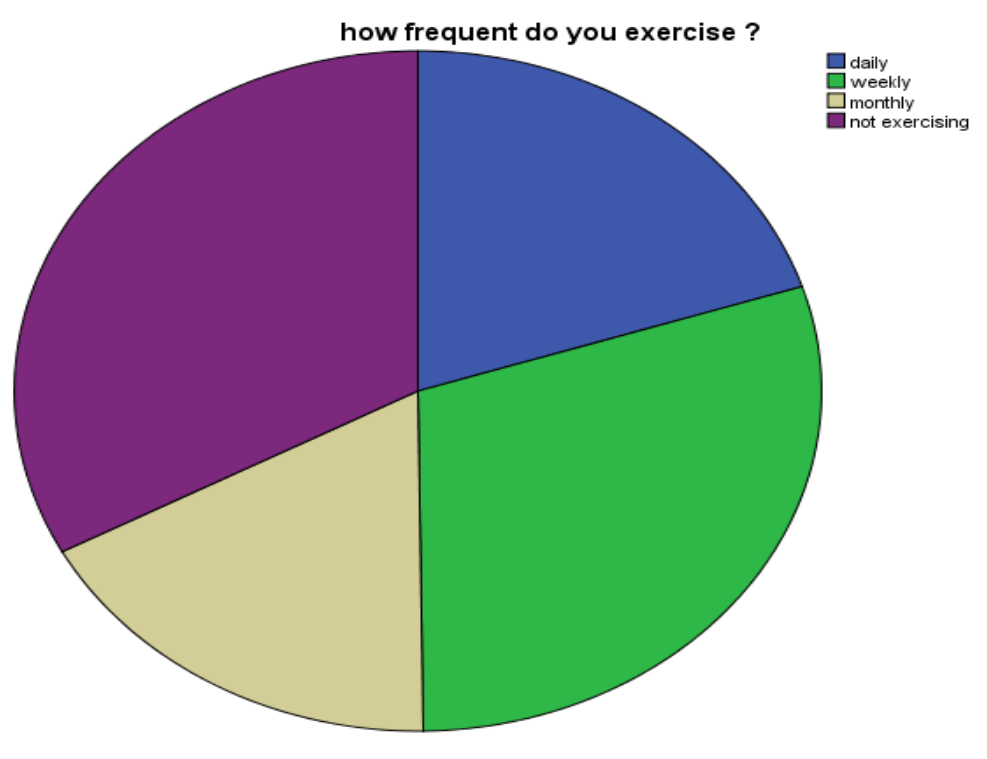




\begin{tabular}{|l|l|l|l|l|l|}
\hline \multicolumn{2}{|l|}{ Smoking state } & Frequency & Percent & Valid Percent & Cumulative Percent \\
\hline \multirow{3}{*}{ Valid } & yes & 830 & 25.7 & 25.7 & 25.7 \\
\cline { 2 - 6 } & no & 2400 & 74.3 & 74.3 & 100.0 \\
\cline { 2 - 6 } & Total & 3230 & 100.0 & 100.0 & \\
\hline
\end{tabular}

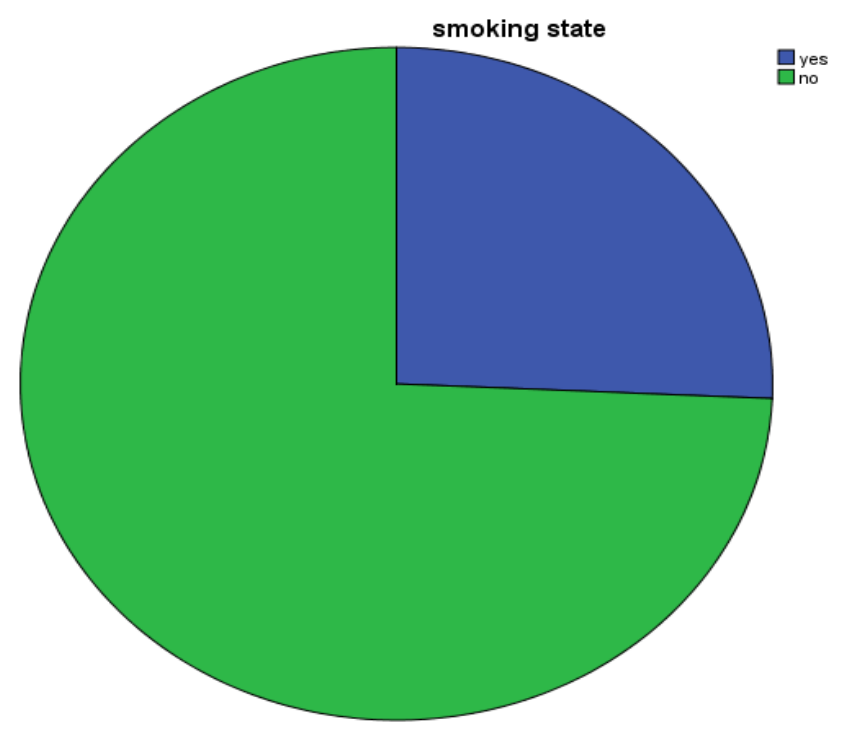

\begin{tabular}{|c|c|c|c|c|c|}
\hline \multicolumn{6}{|c|}{ have you been diagnosed with HTN } \\
\hline & & Frequency & Percent & Valid Percent & Cumulative Percent \\
\hline \multirow[t]{3}{*}{ Valid } & yes & 383 & 11.9 & 11.9 & 11.9 \\
\hline & no & 2847 & 88.1 & 88.1 & 100.0 \\
\hline & Total & 3230 & 100.0 & 100.0 & \\
\hline
\end{tabular}

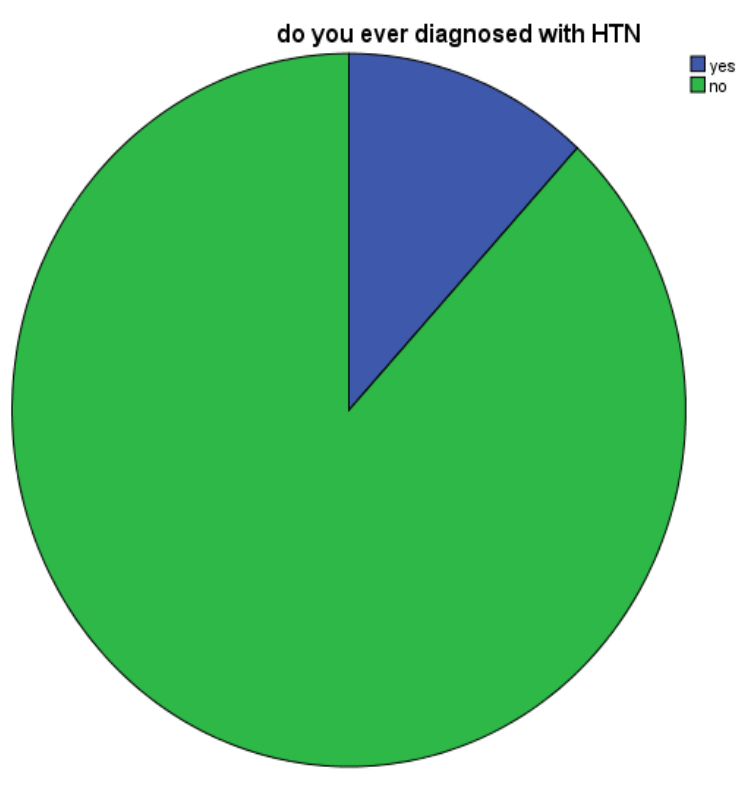




\begin{tabular}{|c|c|c|c|c|c|}
\hline \multicolumn{6}{|l|}{ bmi2 } \\
\hline & & Frequency & Percent & Valid Percent & Cumulative Percent \\
\hline \multirow[t]{6}{*}{ Valid } & $<18.5$ & 182 & 5.6 & 5.9 & 5.9 \\
\hline & $18.5-24.9$ & 1145 & 35.4 & 37.3 & 43.2 \\
\hline & $25-29.9$ & 948 & 29.3 & 30.9 & 74.1 \\
\hline & $30-39.9$ & 645 & 20.0 & 21.0 & 95.1 \\
\hline & $>39.9$ & 151 & 4.7 & 4.9 & 100.0 \\
\hline & Total & 3071 & 95.1 & 100.0 & \\
\hline Missing & System & 159 & 4.9 & & \\
\hline \multicolumn{2}{|l|}{ Total } & 3230 & 100.0 & & \\
\hline
\end{tabular}

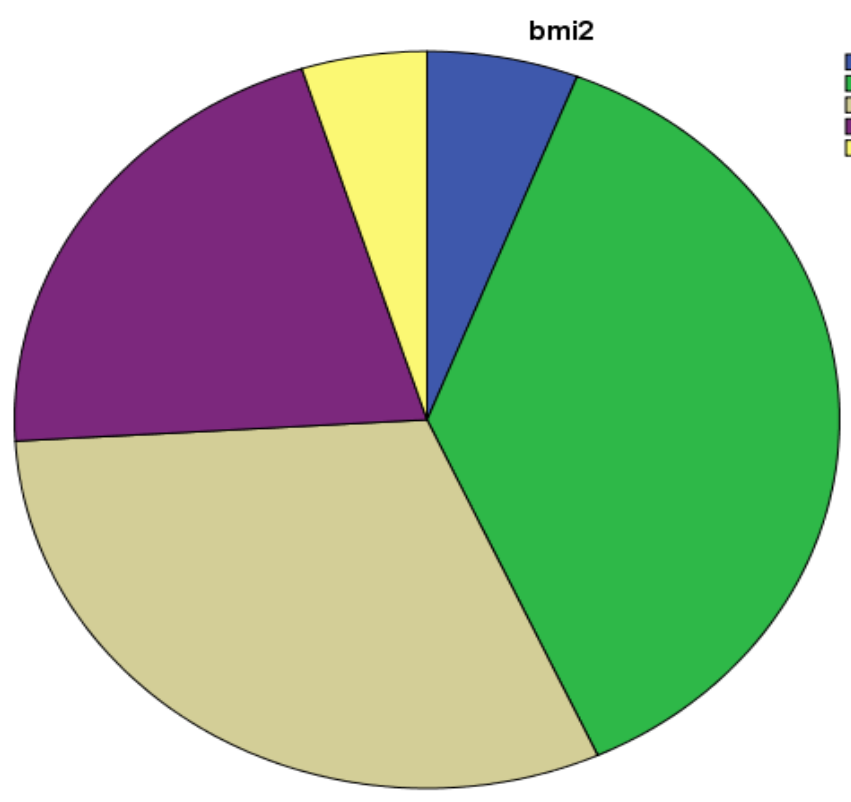

\begin{tabular}{|c|c|c|c|c|}
\hline \multirow{2}{*}{\multicolumn{5}{|c|}{ Have you ever been diagnosed with HTN * nationality Crosstabulation }} \\
\hline & & & & \\
\hline & & \multicolumn{2}{|c|}{ nationality } & \multirow[t]{2}{*}{ Total } \\
\hline & & Saudi & non Saudi & \\
\hline \multirow[t]{2}{*}{ Have you ever been diagnosed with HTN } & yes & $12.1 \%$ & $10.6 \%$ & $11.9 \%$ \\
\hline & no & $87.9 \%$ & $89.4 \%$ & $88.1 \%$ \\
\hline \multicolumn{2}{|l|}{ Total } & $100.0 \%$ & $100.0 \%$ & $100.0 \%$ \\
\hline
\end{tabular}

\begin{tabular}{|c|c|c|c|c|}
\hline \multicolumn{5}{|c|}{ Have you ever been diagnosed with DM? * do you ever diagnosed with HTN Crosstabulation } \\
\hline & & \multicolumn{2}{|c|}{ Have you ever beendiagnosed with HTN } & \multirow[t]{2}{*}{ Total } \\
\hline & & yes & no & \\
\hline \multirow{2}{*}{$\begin{array}{l}\text { Have you ever been diagnosed with } \\
\text { DM }\end{array}$} & yes & $41.5 \%$ & $5.4 \%$ & $9.7 \%$ \\
\hline & no & $58.5 \%$ & $94.6 \%$ & $90.3 \%$ \\
\hline \multicolumn{2}{|l|}{ Total } & $100.0 \%$ & $100.0 \%$ & $100.0 \%$ \\
\hline
\end{tabular}




\begin{tabular}{|c|c|c|c|c|}
\hline \multicolumn{5}{|c|}{ smoking state * have you ever been diagnosed with HTN Crosstabulation } \\
\hline \multicolumn{5}{|c|}{$\%$ within do you ever diagnosed with HTN } \\
\hline & & \multicolumn{2}{|c|}{ Have you ever been diagnosed with HTN } & \multirow[t]{2}{*}{ Total } \\
\hline & & yes & no & \\
\hline \multirow[t]{2}{*}{ smoking state } & yes & $31.9 \%$ & $24.9 \%$ & $25.7 \%$ \\
\hline & no & $68.1 \%$ & $75.1 \%$ & $74.3 \%$ \\
\hline Total & & $100.0 \%$ & $100.0 \%$ & $100.0 \%$ \\
\hline
\end{tabular}

\begin{tabular}{|l|l|l|l|l|}
\hline Have you ever been diagnosed with HTN * medical insurance Crosstabulation \\
\hline \% within medical insurance & medical insurance & \multirow{2}{*}{ Total } \\
\cline { 2 - 5 } & yes & no & \\
\hline \multirow{2}{*}{ Have you ever been diagnosed with HTN } & yes & $13.0 \%$ & $10.9 \%$ & $11.9 \%$ \\
\cline { 2 - 5 } & no & $87.0 \%$ & $89.1 \%$ & $88.1 \%$ \\
\hline Total & $100.0 \%$ & $100.0 \%$ & $100.0 \%$ \\
\hline
\end{tabular}

\section{The Discussion:-}

The purpose of this study was to investigate about the risk factors of hypertension in pre-hypertensive people. This study found most of our participants were Saudi females with different age group and equal percentage of the marital status between married and single with small percentage of divorced people, not all our participants were covered by medical insurance only half of the participant had insurance and could afford medical expenses. It was found that there was no significant difference between female and male who were diagnosed with hypertension. The interesting significance we found in this study, many of our participant with hypertension had no positive family history but they were either smokers or morbidly obese or even both risk factors. There was no correlation between exercise and hypertension in this study.

\section{Conclusion:-}

Hypertension is a silent disease that is only diagnosed incidentally. Although it is risk factors consider to be modifiable except for (age, gender and genetic predisposing) the majority of patients are asymptomatic. An early detection and evaluation of those with or at risk of hypertension could prevent an early organ damage with left ventricle hypertrophy. The analysis of this study proves that most our society suffer from early hypertension due to bad eating habits and consummation of energy drinks which lead to obesity, diabetes which is another risk factors of hypertension. Our plan is to reduce the impact of risk factors on developing hypertension in our community by $10 \%$ each year with following preventive measures includes educating schools, universities and factories along with awareness campaign, targeting the social media and smoking caseation program and following up with patients for the next five years. We must emphasize that management of the modifiable risk factors of hypertension reduces the risk of cardiovascular insult, renal damage, stroke and ischemic heart disease.

\section{Reference:-}

1. SHMS, Saudi hypertension management society. 2011

2. Medscape (1994) overview of hypertension, 30 $0^{\text {th }}$ Sep 2014 [Online] available from http://emedicine.medscape.com/article/241381-overview [Accessed: June 20, 2016]

3. PUBMD Health (1836), Hypertension, 22 $2^{\text {nd }}$ Feb 2012 [Online] available from http://www.ncbi.nlm.nih.gov/pubmedhealth/PMH0041082/\#conssmbp.s3 [Accessed: June 20, 2016]

4. WebMD (2005), Hypertension/High blood pressure, $12^{\text {th }}$ Jun 2015 [Online] available from http://www.webmd.com/hypertension-high-blood-pressure/guide/whypertension-diagnosing-high-bloodpressure [Accessed: June 20, 2016] 